\title{
Introduction to Make, Mistake, Journey: Practice-led research and ways of learning
}

\author{
ANNA PIPER, Nottingham Trent University \\ ALICE CLOUGH, Nottingham Trent University
}

Welcome to a special issue of Networking Knowledge, focused on the role of practice in research across a broad range of disciplines. Practice-orientated methodologies (for example practice-led research, practice-based research, etc.) have become pertinent in recent years, alongside discussions about the nature of academic knowledge and perceived distinctions between theory and practice. Similarly, an increasing focus on the relationship between mind, body, and world has led to questions about the role of the researcher, and challenges to academia's requirement for objectivity and 'truth'. Studies increasingly acknowledge or embrace the presence of the researcher, or use the body itself as the means of doing research. In these studies, knowledge is both produced and received through the body, in a reflexive and iterative process.

But while practice-led methodologies have promoted new ways of knowing through doing, they have also highlighted a number of epistemological questions:

- How can theory and practice be integrated and used together holistically?

- How can the merit of practice-led methods be judged within a quantitative academic framework?

- How can practice-led research processes and outputs be understood as equivalent to rather than supplementary to - the written word?

- What are the limits of practice-led research?

This edition of the journal brings together contributions from the fields of architecture, performance, motion graphics, installation art, graphic design, urban planning and photography. The authors provide a small glimpse into increasingly active dialogues around the nature of practice in research. They introduce creative, collaborative, and emergent research methodologies, as well as demonstrating real-world applications of practice-led research to a variety of contexts. They also demonstrate how researcher-practitioners are attempting to challenge the dominance of traditional academic research formats and methodologies, through the communication and dissemination of research outputs and knowledge generated through practice-led research and reflective practice. 
The issue begins with a paper by Emily Hornum, who uses immersive and interactive installations to explore the impact of new media on traditional understandings of the family archive. By using an artistic process that incorporates photographs, videos and personal belongings sourced from her own family, Hornum explores her role as researcher, artist and subject. Hornum's work investigates themes of memory and identity, exploring the 'blurred genres' between subjectivity and objectivity, and arguing for the importance of subjectivity in fostering dialogue disciplines and innovative outcomes.

In our second paper, Helen Norrie - founder of the Regional Urban Studies Laboratory (RUSL) - and Judith Abell investigate collaborative approaches to resolving urban design issues in towns and small cities. RUSL uses design research - a form of practice-led research which aims to bridge the gap between theory and practice by generating questions in an open-ended process. In this paper Norrie and Abell present RUSL as a case study, outlining the project's research aims, methods, and outputs before reflecting on the role of collaboration in design research.

Our third paper comes from Eli Hatleskog, Anna Holder and Anthony Hoete from the field of Architectural Creative Practice Research (ACPR). Considering architectural practice as research, they explore the role of speech as both design skill and research method in architecture, as well as the value of architectural responses to creative practice. The paper makes use of individual voices to explore key themes including what it means to be an architect, the limits of architectural creative practice, and experiences of doing a $\mathrm{PhD}$ in this field. A focus on speech raises questions about the locus and various forms we might understand as 'knowledge', as well as the role of talking in the development of ideas.

Danielle Abulhawa, a performance artist and researcher exploring gendered play in the built environment, considers the knowledge gained through the process of documentation and engaging with reflective documentation. By producing "artists' pages" to record diary entries, public responses to performance and engagements with her examiners, she explores the role of documentation as a site of knowledge production and performance within a thesis.

Belen Cerezo explores the notion of the performance-lecture through her work How to open my eyes?. She questions the nature of the performance-lecture as a critical method in artistic research, arguing that the combined use of performance-lecture and 'performance document' fuses artistic theory and practice, exploring the interplay between thinking, making, and reflection, and challenging established categories relating to the production of academic knowledge.

In 'Method through motion', Arthur Steijn from the Royal Danish Academy of Fine Arts, discusses the development of a design model to address the lack of academic methods and rigour in the field of scenography and motion graphics. Developed through design laboratories and workshops, the design model incorporates procedures, concepts and terminology for the design 
and study of motion graphics in spatial contexts. Steijn provides insights into and reveals aspects of tension between theory and practice in practice-led research.

Maria Zingoni presents the use of a Studio Based Learning methodology to explore real world problems, in the context of an annual Interdisciplinary Cluster Competition (ICC) held in the USA. The competition brings together students from Architecture, Industrial Design, Interior Design, Landscape Architecture and Visual Communication, to work across disciplines and generate holistic and resourceful solutions together. Zingoni discusses the format and structure of the competition, the role of collaboration and the methodology used, before exploring a series of pedagogical issues surrounding the competition.

In our final paper, Brad Tober explores practice-led speculative design as an experimental research methodology. The paper discusses the maker movement and its relationship to the contemporary discipline of design; exploring the democratization of production technologies and its impact on the design profession and the role of the designer. Tober proposes a framework for practice-led speculative design research to allow designers to maintain professional relevance, by positioning them as instigators whose work can inform other designers as well as non-designers.

In preparing the call for papers for this special issue, we were keen to invite submissions that would challenge conventional notions of 'the journal paper'. We felt that the web-based format of Networking Knowledge created opportunities for visual, sonic, or even interactive submissions. We have been pleased to receive papers containing film, image, and first-person narrative; it is with interest, however, that we have noted a sense of reservation in many of the submissions. While the rhetoric around theory and practice may be evolving to challenge academic convention, it is clear that researchers still feel bound to some extent by traditional forms of knowledge dissemination. In practice-led research, 'knowing' implies subjectivity, multiplicity, intuition, evocation and emotion. The challenge continues to be that of developing, revitalising, or perhaps even re-enchanting the ways we think about, communicate and qualify academic knowledge.

Alice Clough is a $\mathrm{PhD}$ candidate in the School of Art and Design at Nottingham Trent University. Her work focuses on material culture, starting with a degree in Archaeology and Anthropology, and followed by an MA in Material and Visual Culture Studies. Her research interests centre around making, the body, and the nature of experience. Alice's current $\mathrm{PhD}$ research looks at the rhythmic and multi-sensory practice of hand weaving in the UK, with a particular focus on arts-informed research and sensory ethnography.

Email: alice.clough@ntu.ac.uk 
Anna Piper is a PhD candidate at Nottingham Trent University; specialising in weaving her practice-led research focuses on the design and production of garments constructed on and wearable from the loom, using hand and digital production techniques. Her research interests include traditional hand weaving practices, digital weaving techniques, sustainable and zerowaste design, embodied knowledge and design innovation.

Email: anna.piper2013@my.ntu.ac.uk 